aniki

Revista Portuguesa da Imagem em Movimento Portuguese Journal of the Moving Image

\section{Mulheres negras na construção de um cinema negro no feminino}

\author{
Edileuza Penha de Souza ${ }^{1}$
}

\title{
Introdução
}

\author{
Ancestrais \\ tecnologias curativas \\ anciãs \\ tecnologias orgasmativas \\ dazantiga \\ tecnologia contraceptivas \\ (famoso "cola-velcro" é pura \\ tecnologia dazamiga
}

(Trecho do poema "Baleias", de Tatiana Nascimento)

A pesquisa A cara do cinema nacional: gênero e cor dos atores, diretores e roteiristas dos filmes brasileiros (2002-2012) (Candido et al. 2014), do Grupo de Estudos Multidisciplinares da Ação Afirmativa (GEMAA), ligado à Universidade do Estado do Rio de Janeiro (UERJ), constata a exclusão de mulheres negras do cinema nacional. Tal estudo, coordenado por Marcia Rangel Cândido e Luiz Augusto Campos, desenvolveu uma análise quantitativa dos filmes nacionais de maior bilheteria entre 2002 e 2012, observando os vinte lançamentos nacionais de maior bilheteria em cada ano quanto à cor (raça) e gênero de atores, diretores e roteiristas.

Chama atenção a total ausência das mulheres negras nessas produções, "69\% dos roteiristas dos filmes analisados são homens brancos, $24 \%$ são mulheres brancas e $3 \%$ são homens negros"; no que diz respeito a elenco, "o espaço das mulheres negras é reduzido: $5 \%$ contra $45 \%$ de homens brancos, $35 \%$ de mulheres brancas e $15 \%$ de homens negros". Esses números são ainda mais desiguais quando analisam a direção: "Entre os filmes analisados, $84 \%$ dos diretores são homens brancos, $14 \%$ são mulheres brancas e $2 \%$ são homens negros". Ou seja, não há nenhuma mulher negra realizadora. (Candido et al. 2014).

Nesse contexto, se situa a proposta deste trabalho que visa, a partir da trajetória profissional da cineasta negra Adélia Sampaio, elaborar uma apresentação panorâmica de algumas das mais

\footnotetext{
${ }^{1}$ Universidade de Brasília, Campus Universitário Darcy Ribeiro, Brasília, CEP 70 910-900, Distrito Federal, Brasil.
} 
importantes cineastas negras brasileiras e de como elas incorporam as questões de gênero e raça em suas produções. Logo, este trabalho organiza um breve histórico da produção dessa e outras diretoras, que são invisibilizadas pelo circuito midiático, mas que se mantêm como referência nas obras de cineastas negras contemporâneas. Esse breve percurso histórico contempla em linhas gerais o legado do cineasta Zózimo Bulbul e a cinematografia de Adélia Sampaio, pontuando os principais desafios e significados que podem ser vislumbrados quando quem faz cinema é uma mulher negra.

Este trabalho ancora-se na compreensão do cinema negro como produção de intelectuais e cineastas negros e negras. Adota também como perspectiva metodológica a filosofia ancestral do "vividoconcebido" como possibilidade concreta de se pensar e construir uma produção negra midiática e como se constitui como linguagem, símbolos e nos orienta que é possível transcender da porteira para dentro $^{3}$, pois é esse o processo que buscamos ao construir um cinema representativo da territorialidade e a comunalidade negra e do patrimônio imaterial afro-brasileiro (Souza 2008, 2010). Tratase, portanto, de um cinema que nos possibilita dar continuidade à memória ancestral do povo negro, e nos propicia a harmonia cósmica, e a linguagem onde se expressa essa forma de ser e de estar no mundo (Luz 2000).

\section{Cinema no Brasil: lacunas e silêncios}

Desde seus primórdios, a feitura do cinema tem constituído um espaço predominantemente dominado por homens brancos. Isso não é diferente no Brasil, o que muitas vezes explica a falta de referências femininas na função de diretoras, já que ainda é recente o reconhecimento do trabalho de diretoras pioneiras como Cleo de Verberena $^{4}$, Carmen Santos ${ }^{5}$ e Gilda de Abreu ${ }^{6}$.

\footnotetext{
${ }^{2} \mathrm{O}$ encontro com a metodologia do vivido-concebido, desde dentro, para desde fora, busca construir um trabalho acadêmico com emoção, uma vez que, por essa abordagem, pode-se estabelecer um enfoque analítico-descritivo sobre a territorialidade e a comunalidade características da população e do patrimônio imaterial afro-brasileiro. Exploram-se aspectos da pesquisa qualitativa e quantitativa e a narrativa de todo o universo "vivido-concebido". Em outras palavras, busca-se adotar referências teóricas que permitam abordar a diversidade humana, expressa em diferentes maneiras de interpretar o mundo físico e social, de interpretar e viver as relações entre as pessoas, seus grupos, entre elas e o ambiente em que transitam, modificam, de interpretar a si mesmas e suas realizações (Souza, 2008).

3 "Da porteira pra dentro, da porteira pra fora", metáfora da territorialidade da tradição nagô, usada por Mãe Senhora (Osun Miuwá, lyalorisá nilê Asé Opó Afonjá). A expressão caracteriza as relações da comunidade religiosa com a sociedade envolvente, de valores distintos, na dinâmica da pluralidade sociocultural brasileira. Essa expressão tem sido adotada por um grupo de pesquisadores para pensar o processo civilizatório africano no Brasil, e mostrar a importância da presença histórica, social e cultural do negro na constituição da identidade nacional brasileira.

4 Nome artístico de Jacyra Martins da Silveira, atriz e cineasta brasileira. É considerada a primeira mulher brasileira a dirigir um filme, O Mistério do Dominó Preto (1931), que também produziu e atuou.
} 
Nesse sentido, vale salientar a atuação de Adélia Ferreira Sampaio (Fig. 1), que foi a única mulher negra que esteve na direção de longas-metragens de ficção nos anos 1980, ou seja, antes do "cinema da retomada", expressão que designa o efetivo retorno da produção cinematográfica brasileira após a extinção da Embrafilme (órgão governamental de fomento ao cinema), no Governo de Fernando Collor (15 de março de 1990 a 29 de dezembro de 1992). O filme Carlota Joaquina, de 1995, dirigido por Carla Camuratti, marca o início da retomada no cinema nacional, que passa a utilizar outras vias para a produção e a distribuição dos filmes, como por exemplo, as leis estatais de incentivo à cultura e as parcerias com a iniciativa privada. Outro aspecto relevante deste período foi o aumento da participação feminina, com um boom de cineastas (Borges 2007; Caetano 2007).

O trabalho de Adélia Sampaio está consolidado na história do cinema brasileiro produzido por mulheres, como Zélia Costa, Helena Solberg, Ana Carolina, Lenita Perroy, Suzana Amaral, Teresa Trautman e outras tantas que, como Lucy Barreto, Nazaré Conceição Sena, Tizuca Yamasaki, Carla Camurati e Norma Bengell, foram responsáveis pelo "cinema de retomada" nos anos 1990.

\section{Adélia Sampaio: uma cineasta negra até recentemente apagada da história do cinema brasileiro}

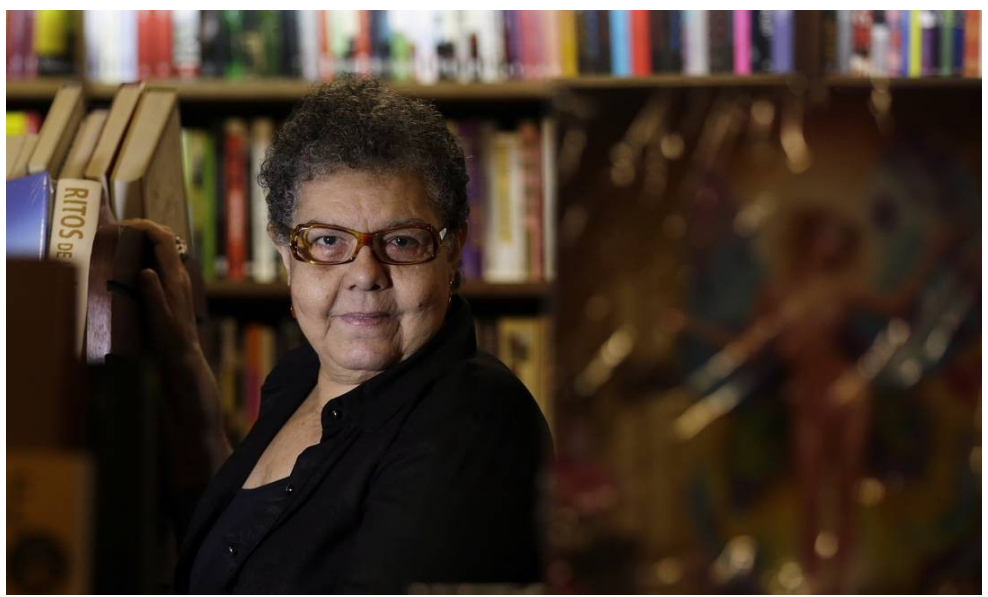

Figura 1 - Adélia Sampaio | ( C Gustavo Miranda / Agência O Globo

Sampaio nasceu em 20 de dezembro de 1944, na cidade de Belo Horizonte, Minas Gerais. Entrou pela primeira vez numa sala de cinema com quatorze anos. No dia 2 de junho de 1969 iniciava sua carreira na Difilm - Distribuidora de Filmes Ltda., produtora e distribuidora de nomes ligados ao Cinema Novo, como Luiz Carlos

\footnotetext{
${ }^{5}$ Maria do Carmo Santos Gonçalves, a Carmem Santos, foi uma das primeiras mulheres a produzir e dirigir filmes para o cinema brasileiro. Roteirizou, dirigiu, produziu e foi atriz do filme Inconfidência Mineira (1948).

${ }^{6}$ Diretora, roteirista, cantora, atriz e escritora, dirigiu O Ébrio (1946), Pinguinho de Gente (1949) e Coração Materno (1951).
} 
Barreto e Joaquim Pedro de Andrade, criada em 1967. Paralelamente a seu trabalho de telefonista, organizava sessões em $16 \mathrm{~mm}$ para cineclubistas. Nos anos de 1970, Sampaio se firmou como produtora e foi responsável pela produção de três filmes importantes: O segredo da rosa, dirigido por Vanja Orico (1974), no qual, além da produção executiva, foi também roteirista; Ele, ela, quem? (1977), de Luiz de Barros (Lulu de Barros); O seminarista (1977), de Geraldo Santos Pereira.

Junto com sua irmã Eliana Cobett $^{7}$, na época casada com o cineasta William Cobett, trabalhou na produção dos filmes do cineasta O monstro de Santa Teresa (1975) e O grande palhaço (1980). Nessas produções, Sampaio atuou em várias frentes: foi produtora, produtora executiva, continuísta, maquiadora. Assim, após trabalhar em parceria com grandes nomes do cinema brasileiro, como por exemplo em Parceiros da aventura (1980), de José Medeiros, e Um menino... uma mulher (1980), de Roberto Mauro, e já com a experiência de ter dirigido seus próprios curtas Denúncia vazia (1979), Agora um deus dança em mim (1979), Adulto não brinca (1979) e os documentários Na poeira das ruas (1982) e Cotidiano (1982), Sampaio dirigiu, em 1984, Amor maldito, seu primeiro longa-metragem, que é considerado o primeiro filme lésbico do cinema nacional brasileiro. O roteiro de José Louzeiro baseou-se em crônicas jornalísticas de um caso ocorrido em Jacarepaguá, Rio de Janeiro. A repercussão de Amor maldito foi quase nula afora uma resenha de Leon Cakoff na Folha de S. Paulo, que descreveu o filme como "um oásis no meio de tanto filme pornográfico":

A produção é marcada pelas agruras da indústria cinematográfica nacional naquele momento, especialmente em São Paulo, assolada pela onda do filme pornográfico. Lidando com tema tabu, teve de ser feito num esquema cooperativo (na conhecida "broderagem", que então era mais comum à produção teatral) (Cakoff 1984).

Em 1987, Sampaio dirigiu o documentário Fugindo do passado - um drink para Tetéia e História Banal, sobre memórias da ditadura. Em 2004, codirigiu, com Paulo Markum, para a televisão, AI-5 - o dia que não existiu e, a partir de então, passou a realizar vários programas de televisão. Em 2018, dirigiu $O$ mundo de dentro, que estreou no $29^{\circ}$ Festival Internacional de Curtas-Metragens de São Paulo. Mais recentemente, Adélia Sampaio tem trabalhado no projeto do filme de longa-metragem $A$ Barca das Visitantes, que retrata de forma poética a perseverança e luta pela liberdade do seu companheiro, o jornalista Pedro Porfirio, preso pela polícia durante a ditadura militar. Em 2016, a jornalista Juliana Gonçalves e a cineasta Renata Martins fizeram uma longa entrevista com Sampaio para o site Blogueiras

\footnotetext{
${ }^{7}$ Responsável pelas produtoras Tabajara Filmes e Difilmes, foi a primeira mulher produtora executiva de filmes no Brasil. Durante a ditadura militar, teve sua casa e a Tabajara Filmes invadidas. No final da vida, residia em Florianópolis, onde desenvolveu projetos sociais como o "Crescendo com Arte", na comunidade de Canasvieiras.
} 
Negras. Ao falar sobre Amor Maldito, a diretora relembra: “(...) O filme foi rodado em sistema de cooperativa (...). Terminamos o filme e na hora da exibição nenhum dono de cinema queria o filme. Até que o dono do Cine Paulista me propõe transvestir a divulgação da porta como se fosse um filme pornô. Pensei, discuti com a galera $\mathrm{e}$ topamos. Deu certo".

Os filmes de Adélia Sampaio são alicerçados nos problemas sociais. Buscando fatos verídicos como inspiração, ela retrata temas sensíveis que envolvem diferentes gerações de velhos, adultos, jovens e crianças; trazendo para as telas temáticas como afeto, amor e violência, edifica um cinema brasileiro como espaço de pertencimento e de referência da história. Em entrevista em 2014, a cineasta declara:

É desafiante nascer negra num país que tem embutido em seu bojo o preconceito de cor e também um preconceito social. Como uma negra criada num asilo pode se tornar uma cineasta? Tem um preço, foi sofrido e por este motivo dedico o Amor Maldito aos meus filhos (Souza 2014).

Vale destacar que os negativos dos seus curtas armazenados no MAM (Museu de Arte Moderna) estão desaparecidos, impedindo assim não apenas sua divulgação, como também pesquisas aprofundadas sobre a sua relevância. Por outro lado, diversos grupos têm prestado homenagens à cineasta: "Mostra Competitiva de Cinema Negro Adélia Sampaio" ", que integrou a programação do "I Encontro Internacional de Cineastas e Produtoras Negras", realizado de 21 a 25 de agosto de 2017; Cartel Adélia9; Cineclube Adélia Sampaio $^{10} ; 26^{0}$ Festival Mix Brasil ${ }^{11}$, entre muitos outros. Esses eventos firmam o reconhecimento de Sampaio como a primeira mulher negra, cineasta, diretora e produtora, que aos 75 anos inspira uma geração de jovens que se estabelecem como diretoras, roteiristas e produtoras negras no cinema brasileiro.

\footnotetext{
8 A Mostra é uma realização no âmbito da disciplina Etnologia Visual da Imagem do Negro no Cinema, da Universidade de Brasília (UnB), completou sua terceira edição em 2019, tendo por objetivo promover o intercâmbio entre realizadoras negras do audiovisual.

9 Coletivo composto por profissionais negras do audiovisual, moradoras da periferia do Rio de Janeiro.

${ }^{10}$ Criado em 2016 em Porto Alegre, capital do estado do Rio Grande do Sul, pelo Coletivo Criadoras Negras.

${ }^{11}$ Em 2018, o Festival prestou sua homenagem a Adélia Sampaio com o programa "Foco: Pioneirismo lésbico na direção".
} 


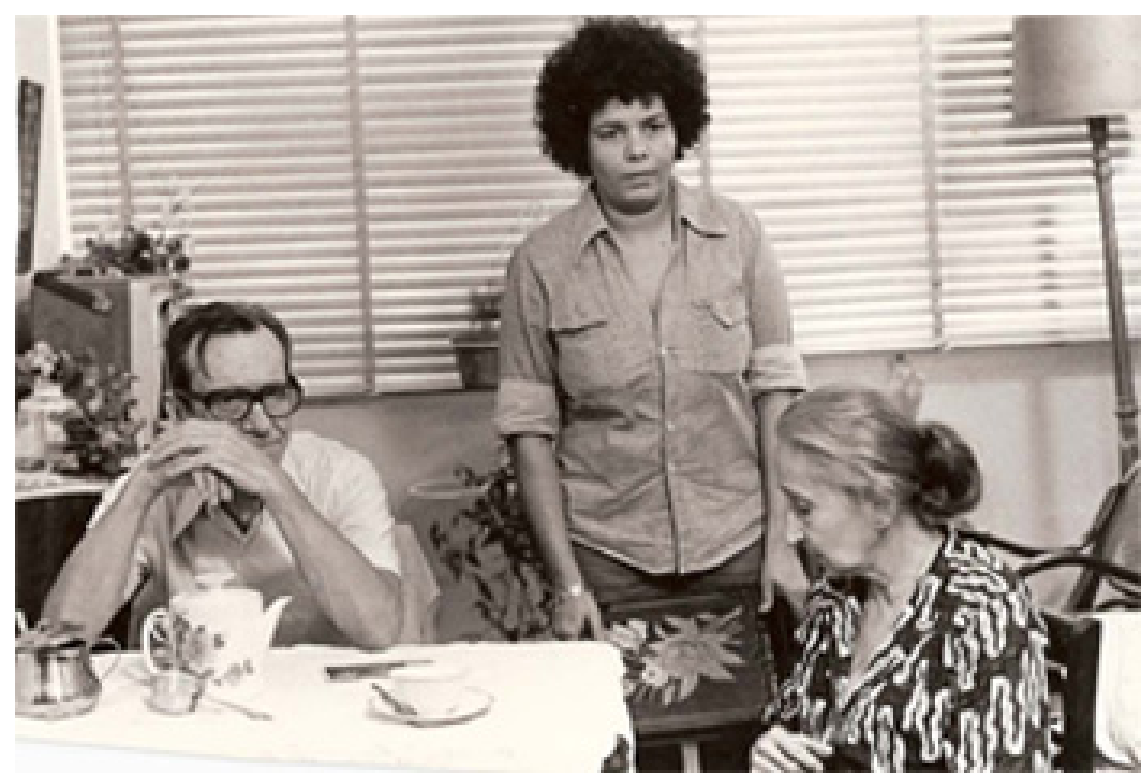

Figura 2 - Adélia Sampaio na filmagem do curta Denúncia vazia (C) Site Mulheres no cinema brasileiro

Essa autonomia na construção fílmica de identidades e representações, segundo Suely Carneiro (2003), "transforma as mulheres em novos sujeitos políticos". A partir do lugar em que estão inseridas, elas assumem perspectivas distintas do olhar convencional, "que desencadeiam processos particulares subjacentes na luta de cada grupo particular". Ou seja, grupos de mulheres negras cineastas encontram no cinema demandas específicas que, “essencialmente, não podem ser tratadas, exclusivamente, sob a rubrica da questão de gênero se esta não levar em conta as especificidades que definem o ser mulher [negra] neste e naquele caso" (Carneiro 2003, 119).

Tais perspectivas têm possibilitado um cinema negro no feminino, alicerçado na diversidade do combate ao racismo, ao machismo, à homofobia e a todo e qualquer tipo de preconceitos e discriminações. São possibilitadas pela linguagem e pela narrativa cinematográfica, se consolidam para além da pluralidade e da territorialidade, pois, como afirmou Lélia Gonzalez: "a tomada de consciência da opressão ocorre, antes de tudo, pelo racial" (Bairros 2007, 56). Ao arquitetarmos o cinema brasileiro, nós mulheres negras elencamos os ensinamentos de nossas(os) ancestrais, pois esses são as principais referências de linguagens, valores, desejos e práticas que ancoram nossa existência no contínuo civilizatório africano (Souza, 2008).

\section{Do conceito à produção: trilhando um cinema negro no Brasil}

Desde 1912, quando Willian D. Foster lançou seu primeiro filme (The Railroad Porter) dirigido e representado por negros, os debates sobre cinema negro foram acompanhados do progressivo aumento dos espaços de representação de homens e mulheres negras no 
cinema e no palco. A Foster Photoplay Company, já nas suas pequenas produções, foi a primeira a apresentar os afroestadunidenses como humanos no cinema. Até então, a maioria dos(as) personagens negros(as) que se via era representada por atores e atrizes brancas usando maquiagem preta (blackface). Assim como a Foster Photoplay Company, a Lincoln Picture Company e muitas outras empresas dirigidas por negros deixaram suas marcas em diversos filmes, por seu histórico ou temas, narrativas e estilos. Cunhando o cinema negro estadunidense, essas empresas trouxeram para as telas histórias de vida intimamente ligadas às questões sociais, políticas e econômicas da comunidade negra. Essas empresas, portanto, buscaram romper as representações negativas de negros e negras no cinema hegemônico, "dando atenção ao conflito desigual entre os atores negros e os papéis estereotipados que lhe são oferecidos" (Shoat e Stam 2006, 286).

No Brasil, ainda que ocorra atuação de negros e negras desde o primeiro período do cinema, já nos tempos do cinema mudo a representação de homens e mulheres negras ocupa uma posição marginal em relação a sua imagem. Tal atuação revela ainda que o processo de escolha de um determinado grupo ou pessoa demonstra a dimensão política das práticas de representação, e que, muitas vezes, denuncia o poder dos grupos dominantes (Carvalho 2005). Essas escolhas estão muito bem evidenciadas no documentário $A$ negação do Brasil (Araújo 2000). Entre vários depoimentos, atores e atrizes negras falam de suas carreiras, dos(as) personagens que representaram, das discriminações e preconceitos a que foram submetidos ao longo da história das telenovelas no Brasil. Ao analisar as influências das telenovelas brasileiras que foram ao ar de 1963 a 1997, Joel Zito acaba por criar um processo de identidade étnica, "fazendo um verdadeiro manifesto pela incorporação positiva do negro nas imagens televisivas do país” (Souza 2013, 66).

Em 1998, um grupo de documentaristas e curta-metragistas negros se uniu no sentido de divulgar mutuamente seus trabalhos. No ano seguinte, Jefferson De e Daniel Santiago organizaram, dentro do $11^{\circ}$ Festival Internacional de Curtas de São Paulo, um encontro de cineastas negros brasileiros, onde lançam o "Movimento Dogma Feijoada", que proclamava sete mandamentos ou regras para o cinema negro: 1) o filme tem de ser dirigido por um realizador negro; 2) o protagonista deve ser negro; 3 ) a temática do filme tem de estar relacionada com a cultura negra brasileira; 4 ) o filme tem de ter um cronograma exequível; 5) personagens estereotipados, negros ou não, estão proibidos; 6) o roteiro deverá privilegiar o negro comum brasileiro; 7) super-heróis ou bandidos deverão ser evitados (Carvalho 2005, 96).

Nesse encontro, apenas uma mulher foi citada, a historiadora, cineasta e produtora cultural Lilian Solá Santiago, não por acaso irmã do cineasta Daniel Santiago. Desde o lançamento do Manifesto Dogma, Lilian Santiago participou da produção de dezenas de filmes. Na direção, ela assina os filmes Família Alcântara (2005), junto com Daniel Santiago; Balé de Pé no Chão - a dança afro de Mercedes 
Baptista (2006), em parceria com Marianna Monteiro, e Graffiti (2008). Lilian foi responsável pela concepção e curadoria da Mostra "Espelho Atlântico - Mostra de Cinema da África e da Diáspora”, que teve a sua terceira edição no Rio de Janeiro em maio de 2010. Em 2006, a cineasta recebeu o Prêmio Zumbi dos Palmares, honraria outorgada pela Assembleia Legislativa de São Paulo aos que se destacam por suas ações afirmativas em defesa da promoção da igualdade racial no estado de São Paulo.

Nos anos de 1990, outras mulheres negras já estavam realizando seus trabalhos, dentre elas a artista multimídia Iléa Ferraz, ainda que segundo a própria atriz "[...] é complicado se titular como cineasta, numa época em que ninguém estava fazendo cinema" (Souza 2014). Iléa Ferraz atua, canta, dirige, escreve, produz, ilustra, cria e executa projetos cenográficos. Como cineasta, dirigiu e produziu os filmes Dura (1994) e O Cheiro da Feijoada (2011). Nesse sentido, embora o Movimento Dogma Feijoada tenha possibilitado a discussão sobre a possibilidade de um cinema brasileiro feito por negros, criando uma agenda mínima para pensar um cinema negro, o texto não faz nenhuma referência ao papel da mulher negra no cinema. Em 2001, no 5o Festival de Cinema do Recife, veio a lume o Manifesto do Recife. De caráter prescritivo e mais politizado que o Dogma Feijoada, "o manifesto reivindicava maior participação dos afro-brasileiros não apenas no cinema, mas em todas as esferas da produção audiovisual” (Carvalho 2004, 23). Nesse segundo Manifesto estavam presentes as atrizes Maria Ceiça, Ruth de Souza, Thalma de Freitas. No entanto, mais uma vez, nenhuma menção sobre a presença (ou ausência) negra feminina na direção de televisão e de cinema.

Apesar de suas inúmeras lacunas, ambos os manifestos são, para nós, referências fundamentais do Cinema Negro Brasileiro. Os trabalhos dos cineastas que compuseram esses dois momentos históricos do cinema brasileiro, bem como tantos outros que vêm surgindo a partir de então, têm tornado o Cinema Negro passível de intervenção social. Nesse sentido, para conceituar um Cinema Negro no feminino é necessário definir critérios que nos permitam reconhecer e identificar características específicas de combate ao racismo, ao machismo e à homofobia, ao mesmo tempo em que essas obras cinematográficas atuam no sentido de promover a diversidade e a identidade negra, e, ainda, nos possibilitam enquadrar diferentes estilos naquilo que se convencionou chamar de gênero cinematográfico. Nesse sentido, Souza (2013, 63) afirma: “(...) me aproprio de um conjunto de critérios e passo a classificar e definir novos conceitos do gênero Cinema Negro. Para arquitetar o conceito de Cinema Negro, evoco cineastas e acadêmicos cujas obras têm transformado teorias e ideologias em lições de vida”.

A adesão a esse conceito de cinema negro nos permite identificar então gerações sucessivas de militantes negros e negras que somente foram capazes de demarcar teorias e, consequentemente, ideologias, por meio de suas experiências de vida. Em outras palavras, Cinema Negro é um conceito cunhado na 
luta diária de combate ao racismo, ao preconceito e toda e qualquer discriminação. É, pois, um conceito corporificado pela militância negra que se finca no território e na territorialidade e nos orienta que é possível transcender da porteira para dentro, pois é nesse processo "que os integrantes da comunidade compartilham conhecimentos, sentimentos e emoções comuns, que se estabelecem e se fortalecem os vínculos de aliança e se estrutura identidades" (LUZ, 1992, 59).

\section{O cineasta negro Zózimo Bulbul}

Jorge da Silva nasceu em setembro de1937 no Rio de Janeiro. Adotou o nome artístico de Zózimo Bulbul (Fig. 3), Zózimo, apelido recebido na infância, e Bulbul, uma palavra de origem africana incorporada ao nome artístico por volta do final da década de 1960. “A adoção do pseudônimo aponta para o dado político/racial. É parte da reivindicação de uma identidade coletiva, pública e política. Prática recorrente nas décadas de 1970 e 1980 entre artistas e ativistas negros para a construção de uma ancestralidade africana" (Carvalho 2012).

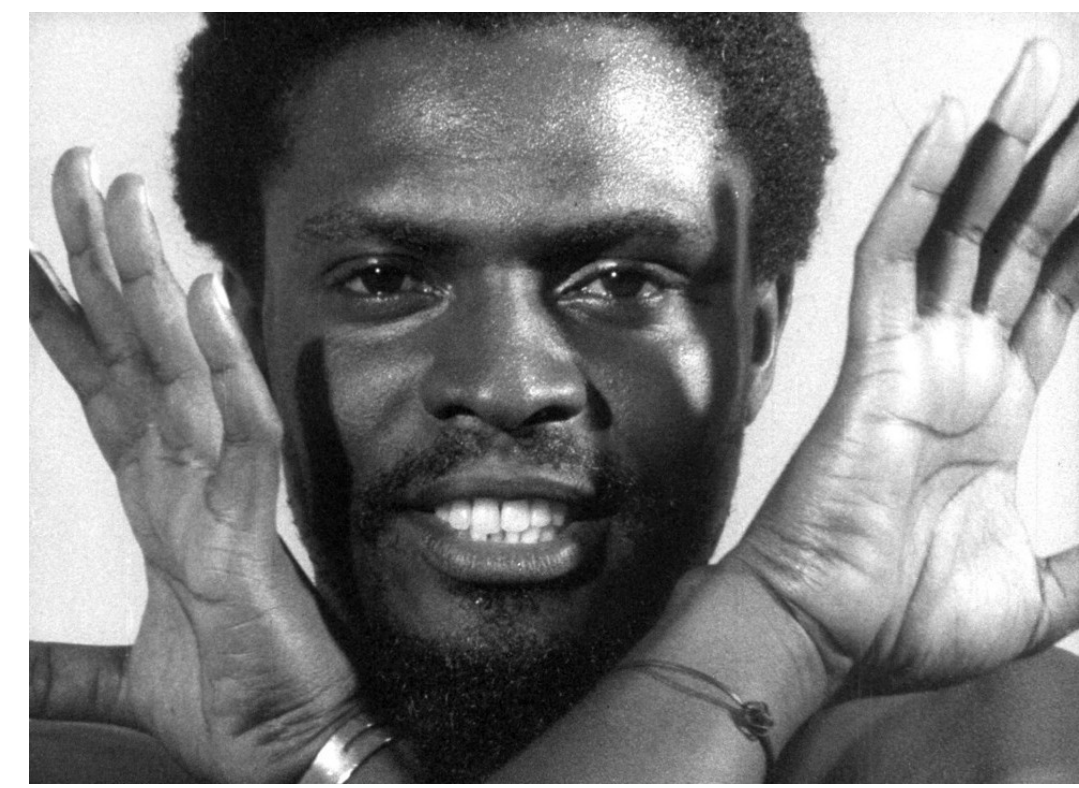

Figura 3 - Zózimo Bulbul em cena do filme Alma no Olho (1973) | C Zózimo Bulbul

Assim como a ancestralidade, a arkhé se caracteriza como vivência inaugural da força de continuidade dos grupos. Para Muniz Sodré $(1998 ; 2005)$ a arkhé se constitui como passado e futuro, possibilita uma continuidade entre deuses, ancestrais e descendentes, estabelece conviver com várias temporalidades e continuidade que se manifestam por meio dos ritos e dos mitos.

E é desse modo que a arkhé do cinema negro feminino se constitui. No reconhecimento das produções cinematográficas de homens e mulheres negras, consideramos importantes as dimensões 
da cosmovisão africana que constitui um cinema diferenciado de abordagens estereotipadas e preconceituosas. Um cinema que vivencia e privilegia o sentir como forma de apropriação ancestral de sua base.

Atualmente reconhecido como o pai do Cinema Negro brasileiro, Zózimo Bulbul construiu sua produção cinematográfica vinculada à militância e ao compromisso com a população negra. Foi o primeiro modelo negro a assinar uma grife de alta-costura e trabalhou, até novembro de 2012, em seu segundo longa-metragem, que não chegou a concluir. Alma no Olho (1973), o primeiro filme dirigido pelo diretor Zózimo Bulbul, inspira-se no livro escrito pelo líder dos Panteras Negras, Eldridge Cleaver, Alma no exílio, publicado originalmente em 1968. Por meio de pantomimas, Zózimo conta a história do negro desde o período colonial escravocrata até os anos do Movimento Black Power. No dizer do cineasta Jeferson De (2013 s/p):

\begin{abstract}
Alma no Olho fundou o que 'conceitualmente' chamo de Cinema Negro Brasileiro, foi dirigido por Zózimo Bulbul (com restos de negativo do filme Compasso de Espera, de Antunes Filho). Com este filme, Zózimo foi prestar contas na Censura e ficou em cana alguns dias. Os milicos queriam saber quem tinha mandado ele realizar o subversivo curta. Para os guardas era óbvio que um negão não poderia ser responsável pela sofisticada obra. Dias depois, veio a solução. Zózimo disse que tinha feito o curta sob ordens de seu amigo, o poeta (e diplomata) Vinicius de Moraes. Aí, obviamente, os fardados pegaram leve e liberaram o cineasta. Esta é apenas uma das centenas de histórias que cercam o filme.
\end{abstract}

Zózimo influenciou a produção de incontáveis diretores e diretoras negros(as). Ao falar de cinema negro ou do negro no cinema, estamos falando de uma história de exclusão que perdura em nossos dias. Entretanto, a vida e obra de Zózimo Bulbul se conecta diretamente com a história do cinema negro brasileiro (SOUZA, 2013).

\title{
Mulheres negras na direção de cinema
}

"O cinema é uma AR-15 e nós negros [e negras] brasileiros[as] sabemos atirar".

Zózimo Bulbul

As reflexões apresentadas confirmam a necessidade urgente de pensarmos um conceito de "Cinema Negro no Feminino". Essa terminologia vem sendo usada no Brasil e no mundo, como um cinema arquitetado por cineastas negras. Em sua maioria, elas são mulheres negras e militantes que encontraram no audiovisual a possibilidade concreta para denunciar e combater o racismo, o machismo, a homofobia, e as múltiplas formas e especificidades de 
discriminações e preconceito tão arraigadas na sociedade. Nessa perspectiva, cresce a atuação de mulheres negras como produtoras, realizadoras, montadoras, cenógrafas, roteiristas, câmeras e diretoras. Entretanto, a participação dessas mulheres na indústria cinematográfica ainda é pouco significativa e quase totalmente silenciada, a exemplo dos trabalhos de Sampaio e outras, como o da atriz e diretora Maria Dealves. Ela dirigiu, roteirizou e atuou no curta Elisa (2001) e no média-metragem Ator profissão amor (2002) - este último, selecionado para o Festival BR 2003 e para ser exibido na Biblioteca Nacional de Paris no evento França/Brasil 2005. Dealves atuou como atriz no teatro, televisão e cinema, tendo participado de mais de cinquenta trabalhos, e faleceu aos 60 anos, no dia 8 de maio de 2008, no Rio de Janeiro.

Outro destaque é a atriz, escritora, roteirista e cantora Dandaara. Carioca, ela dirigiu seu primeiro filme, Gurufim na mangueira, em 2000, e em 2017 estreou o curta-metragem de ficção Desaparecidos, no 25을 Africa Diaspora International Film Festival (ADIFF), em Nova Iorque.

O cinema produzido por mulheres negras tem marcado uma territorialidade sedimentada no desenvolvimento humano, criando e recriando mundos e possibilidades de constituição do indivíduo enquanto parte de um coletivo e duma territorialidade que permite a recriação do mundo e a elaboração de um cinema engajado na luta por uma sociedade mais justa e igualitária (Souza 2008). Ao se tornarem cineastas, essas mulheres rompem com seus lugares de origem, o lugar que lhes estava predestinado por um pensamento racista e sexista, o lugar da doméstica, da lavadeira, da passadeira, daquela que realiza serviços gerais, para assumirem o lugar do comando das câmeras, da produção e direção, construindo seu próprio protagonismo no cinema, como exemplifica a cineasta Viviane Ferreira em entrevista concedida a Souza e Silva (2014).

Eu sou resultado de um projeto político idealizado por mulheres negras. Entre o feminismo branco e o feminismo negro, decidimos montar nosso exército. E fui estudar cinema. E assim conheci o trabalho de Zózimo Bulbul, o pai do cinema negro no Brasil. [Ele] mostrou pela primeira vez conteúdos negros do país pra uma audiência. E chocou. A linguagem audiovisual é uma forma de construir poder, discurso político. O audiovisual constrói personagens com quem as pessoas vão se identificar, se projetar.

Em 2014, Viviane teve seu curta-metragem O Dia de Jerusa selecionado para fazer parte da programação do Festival de Cannes, na França. Em seu primeiro longa-metragem, Um dia com Jerusa (2019), assim como no curta, aborda questões como solidão, solidariedade e afeto. Protagonizado pelas atrizes Léa Garcia e Débora Marçal, se configura como um dos marcos do cinema negro brasileiro da contemporaneidade. A diretora Viviane Ferreira faz parte de uma geração de mulheres negras cineastas, armadas com suas AR-15, diretora da APAN - Associação dxs Profissionais do 
Audiovisual Negro, seus tiros ainda se constituem como complemento de lacunas e omissões da cinematografia brasileira. Juntamente com Viviane, a também cineasta Eliciana Nascimento foi selecionada para Cannes com o curta O Tempo dos Orixás (The Summer of Gods) (2013). As duas foram as primeiras cineastas negras brasileiras selecionadas para o maior festival de cinema mundial.

Eliciana Nascimento é Mestre em Cinema pela San Francisco State University, dirigiu e produziu dois curtas na Bahia, Por Matthew Day Was Born (2011) e The Summer of Gods (2013), coproduziu o documentário Insurreição Rítmica (2009), além de ser fundadora da empresa de produção Candace Cine Vídeo. No segundo semestre de 2011, a Fundação Cultural Palmares (vinculada ao Ministério da Cultura), em conjunto com o Centro Afro-Carioca de Cinema, produziu uma coletânea reunindo em dois DVD a memória dos Encontros de Cinema Brasil África e Caribe (2007, 2008, 2009, 210, 2011). Viviane Ferreira, com o filme Mumbi (2010), e Janaina Oliveira, conhecida pelo nome artístico Re.Fem, com o filme Rap de saia (2008), são as únicas mulheres que fazem parte da coletânea, que contou com a produção de Monalyza Alves e da também cineasta Luana Paschoa. Formada em Design e depois em Direção Cinematográfica na Escola de Cinema Darcy Ribeiro, no Rio de Janeiro, Luana considera-se ainda uma estudante de cinema. Ao lado do Mestre Zózimo, ela fez parte da curadoria dos Encontros de Cinema Negro Brasil, África e Caribe, onde aprendeu que "Cinema negro não é apenas um cinema protagonizado por negros, e sim realizado pelo olhar do negro", afirmou a jovem em entrevista a Souza (2014).

No exército herdado de Zózimo, as artilheiras estão espalhadas pelo Brasil a fora. No Rio de Janeiro, apontam seus fuzis as cariocas Ana Claudia Okuti, Carmem Luz, Franciele Campos, Mariana Campos, Sabrina Fidalgo, Rosa Miranda, Yasmin Thayná e muitas outras, que lançam caminhos ao campo de pesquisa sobre cinema negro.

Autora e diretora do curta Caixa Preta (2009), Ana Claudia Okuti denuncia a violência a que a juventude negra é submetida, retrata como a intolerância e o preconceito podem modificar os caminhos de um jovem negro.

Mariana Campos, jornalista, formada em rádio e TV, nascida e criada em Padre Miguel, subúrbio do Rio de Janeiro, desde muito cedo já sabia que o seu ofício seria a arte. Aos 20 anos, iniciou um curso livre de cinema. Em 2009, participou do projeto Produtora Escola Cinema Nosso. Em seguida, ingressou na Escola de Cinema Darcy Ribeiro, formou-se em Direção Cinematográfica e assina a direção de Amanhecer (2010), curta-metragem de ficção, Hotel da loucura (2014), longa-metragem documental, e Tia Ciata (2017) e Minha História é Outra (2019).

Em São Paulo, vale destacar o trabalho de Juliana Vicente, fundadora da Preta Portê Filmes, onde atua como produtora e 
diretora. Ela estudou Cinema na Fundação Armando Álvares Penteado (FAAP) e na Escola Internacional de Cinema e TV (EICTV), em Cuba. Produziu diversos curtas e atualmente desenvolve o projeto do longa-metragem Lili $e$ as Libélulas, do roteirista e diretor René Guerra. Seus principais trabalhos são: As Minas do Rap (2015); Os Sapatos de Aristeu (2013); Avós (2010); Para Poeta Cego (2012); Cores e Botas (2010). A história de uma menina negra na década de 1980 que sonhava em ser paquita (assistente de palco da apresentadora Xuxa Meneghel) é o foco do curta Cores e Botas. O filme retrata o cotidiano de uma família negra de classe média e das impossibilidades que são impostas às crianças e adolescentes que não correspondem aos padrões de branquitude.

Graduada em Cinema e Audiovisual pela Universidade Anhembi Morumbi e pós-graduada em Linguagens da Arte pela Universidade de São Paulo - USP, a roteirista e diretora Renata Martins tem várias produções em seu currículo, como os curtas Aquém das Nuvens (2010) e Sem Asas (2019); a série televisiva Pedro e Bianca (2014) e a websérie Empoderadas (2015), esta junto com a diretora e roteirista Joyce Prado, projeto que conta histórias de mulheres negras protagonistas de suas atuações. Atualmente, Renata trabalha em vários projetos no Brasil e em Angola; diretora do II Encontro Nacional Empoderadas - Mulheres negras do Audiovisual, desenvolve a série TEZ e se dedica à captação e tratamento do seu primeiro longa-metragem.

$\mathrm{Na}$ Bahia, o estado com a maior população de negros e negras fora do continente africano, em 2008, foi criado o curso de Bacharelado em Cinema e Audiovisual da Universidade Federal do Recôncavo da Bahia (UFRB). Desde a sua primeira turma, formada em 2012, cresce o número de cineastas negras com domínio das linguagens técnicas e estéticas do cinema e audiovisual, como, por exemplo, a jovem Glenda Nicacio. Em 2011, junto com o amigo Ary Rosa, montou a produtora Rosza Filmes, na cidade histórica de Cachoeira, uma das mais importantes da região do Recôncavo. Tratase de uma produtora independente que realiza cinema a partir de processos coletivos e colaborativos, uma das que têm consolidado o cinema negro. Juntos, Glenda e Ary assinam a direção dos dramas Café com Canela ${ }^{12}$ (2017), Ilha (2018) e Até o Fim (2019). Atualmente, a dupla trabalha na finalização do documentário sobre a Irmandade da Boa Morte ${ }^{13}$ e se prepara para gravar a comédia $\mathrm{Na}$

\footnotetext{
12 Rodado no interior da Bahia, "Café com canela" foi exibido em festivais nacionais e internacionais. Premiado como Melhor Filme pelo Júri Popular; Melhor Atriz e Melhor Roteiro, no $50^{\circ}$ Festival de Brasília do Cinema Brasileiro; Melhor Filme de Longa Metragem pelo Júri Jovem, Melhor Filme de Longa Metragem do Prêmio APC e Prêmio Especial do Júri Oficial, no Festival Panorama: Coisa de Cinema (Salvador); Melhor Filme, eleito pelo Júri Jovem e Prêmio Revelação de Direção pelo Coletivo Elviras na $9^{\text {a }}$ Semana - Festival de Cinema (Rio de Janeiro). Internacionalmente, selecionado para 47th International Film Festival Rotterdam dentro da programação do PACT: Pan-African Cinema Today.

13 Datada do século XVI, a Irmandade da Boa Morte é composta unicamente por mulheres negras. Se constitui como uma confraria afro-católica da cidade de Cachoeira, no Recôncavo da Bahia.
} 
rédea Curta. No contexto baiano, destacam-se ainda as seguintes roteiristas e diretoras negras: Larissa Fulana de Tal, Urânia Muzanzu, Pâmela Peregrino, Cintia Maria e Jamile Coelho.

Jamile Coelho e Cintia Maria foram selecionadas pelo Edital de Apoio para Curta-Metragem - Curta-Afirmativo: Protagonismo da Juventude Negra na Produção Audiovisual, com a animação Órun Àiyé - A Criação do Mundo (2015). As roteiristas e diretoras acabaram de estrear a animação em 3D Corações Encouraçados (2019), firmando a animação como um instrumento de educação e combate ao racismo. Sócias da Estandarte Produções, fundada em 2015, na Bahia, atualmente elas desenvolvem e gerenciam o projeto da escola Núcleo Baiano de Animação e Stop Motion - NUBAS ${ }^{14}$ e trabalham na produção da serie Òrun Àiyé.

Nascida sobre o signo de Peixes e filha de Oxum, Urânia Muzanzu afirma que sua formação veio primeiro de seus avós, do mangue, do Pelourinho, e só depois veio da academia. Atuou como jornalista e produtora cultural e, depois de realizar pequenos curtas, foi premiada e reconhecida com os documentários $O$ Primeiro Beijo (2014) e Merê (2018). Atualmente Urânia trabalha na finalização do roteiro de seu primeiro longa-metragem.

Essas cineastas e muitas outras são responsáveis por construírem um cinema de identidade entendido como espaço de pertencimento e, assim, são agentes recriadoras de mundos e de possibilidades de amor e afetos. Ao produzir e dirigir seus filmes, cineastas negras brasileiras têm edificado um modo de fazer cinema que tem como referência a história e a cultura negras.

A partir do reconhecimento da importância do cinema de Adélia Sampaio, muitas mulheres negras consolidam o cinema como um movimento coletivo. Seus filmes, temas e narrativas têm em comum o desenvolvimento da territorialidade e da ancestralidade como prática cultural que se firma nos encontros, mostras, festivais, debates, exibições em cineclubes, homenagens, entre tantos e consecutivos eventos. Elas trazem para o centro do debate interlocuções que consolidam o cinema negro no feminino.

\section{Considerações finais}

Se a representação da imagem da mulher negra no cinema e na sociedade historicamente esteve presa a preconceitos e estereótipos, nota-se que quando as mulheres assumem o comando na produção de cinema elas exercitam a possibilidade de novos olhares e concepções, desde a estética e a linguagem a outros fatores, mais subjetivos, como identidades e representações. Tais trabalhos

${ }^{14}$ Criado em 2014, pela Estandarte Produções, é um estúdio escola, que visa formação profissional na área cinematográfica com foco em animação, através do ensino de diferentes técnicas. O núcleo visa ainda a democratização e o acesso às ferramentas tecnológicas mais avançadas do mercado. 
recusam estereotipias e, portanto, têm possibilitado leitura afetiva, política, geográfica, além de propiciar novas visões de mundo que enfatizam que o cinema pode ser entendido como espaço de manifestação, culturas e identidades, expressões e cidadania. Desse modo, o cinema produzido por cineastas negras tem marcado uma territorialidade sedimentada no desenvolvimento humano, criando e recriando mundos e possibilidades (Souza 2013).

A territorialidade pode ser percebida como espaço de práticas culturais nas quais se criam mecanismos identitários de representação a partir da memória coletiva, das suas singularidades culturais e paisagens, ou seja, resultante de uma unidade construída, em detrimento das diferenças internas. Também tem surgido nos últimos anos trabalhos acadêmicos com o intuito de historicizar a presença de mulheres negras nas produções cinematográficas e analisar os regimes de visibilidade oferecidos às atrizes e cineastas negras (Silva 2016); (Ferreira 2013); (Freitas e Almada 2017). Essas produções interagem com a literatura específica sobre o cinema e possibilitam discussões de gênero e raça, incidindo alusões de amor, negritude e todos os demais elementos que as temáticas do cinema produzido por mulheres negras têm possibilitado.

É oportuno salientar que, ao propor ao campo do cinema estudos específicos sobre a produção de cineastas negras, não se objetiva centralizar uma abordagem sobre minorias, mas compreender que, além das mulheres negras representarem pelo menos um quarto da população brasileira, seus filmes tendem a possibilitar rompimentos com as representações e, ainda, transformam os paradigmas do conhecimento tradicional, impõem "um reexame crítico das premissas e dos critérios do trabalho científico existente" (Scott 1990, 5).

Nesse sentido, para além da pesquisadora, me coloco aqui como uma diretora negra e ressalto que o processo de construir um cinema negro no feminino nos torna também responsáveis por erguer um cinema de identidade entendido como espaço de pertencimento e também recriar mundos e possibilidades de amor e afetos. A responsabilidade social torna nossos trabalhos, mesmo na produção mais imperfeita, um elemento de arte e existência, onde se configura a nossa territorialidade negra, como bem se pode observar nas produções das cineastas negras brasileiras citadas ao longo desse trabalho.

Ao nos conduzir ao mundo da educação formal, e a partir dela o acesso do fazer cinema, nossas matriarcas negras fizeram de nós, cineastas negras, herdeiras de um legado que nos responsabiliza em dar continuidade aos sonhos. Deste modo, para nós, mulheres negras cineastas, o fazer cinema significa estar no mundo, fazer história, fazer cultura, sonhar, cantar, pintar, cuidar da terra, das águas, da natureza, do corpo e do ori ${ }^{15}$; usar as mãos, esculpir, filosofar, aprender, ensina (Freire 1998), pois de outro modo não há um

\footnotetext{
${ }^{15}$ No candomblé, a cabeça, a mente, a inteligência; a alma orgânica, perecível.
} 
cinema negro possível, pois nossa identidade de cineastas negras se define dentro da magnitude interna do desde dentro e nos possibilita arquitetar por meio do cinema a integridade negra, a força vital, o axé e a arkhé de nossa ancestralidade.

\section{BIBLIOGRAFIA}

Araújo, Joelzito. 2006. A Negação do Brasil: o negro na telenovela brasileira. São Paulo: Senac.

Bairros, Luiza. 2006. "Lembrando Lelia Gonzalez". In: Werneck, Jurema; Mendonça, Maisa; White, Evelyn C. (org.). O livro da saúde das mulheres negras - nossos passos vêm de longe. Rio de Janeiro, Criola/Pallas, pp. 42-61.

Borges, Danielle dos Santos. 2007. A Retomada do Cinema Brasileiro: uma análise da indústria cinematográfica nacional de 1995 a 2005. Tese (Doutorado em Ciências da Comunicação). Barcelona: Universidade Autônoma de Barcelona.

Brasil, Ministério da Cultura. s.d. Disponível em: $<$ http://www.cultura.gov.br/noticiasdestaques/-

/asset_publisher/OiKX3xlR9iTn/content/id/1313720>. Acesso em: 12 jan. 2016.

Caetano, Maria do Rosário. 2007. "Cinema brasileiro (1990-2002): da crise dos anos Collor à retomada". In Alceu, Rio de Janeiro, v. 8, n. 15, p. 196-216, jul./dez. Disponível em: $<$ http://revistaalceu.com.pucrio.br/media/Alceu_n15_Caetano.pdf>. Acesso em: 28 nov. 2019.

Cakoff, Leon. 1984. "Um oásis no meio de tanto filme pornográfico". Folha de S. Paulo. 17/08/1984. Disponível em: <http://acervo.folha.uol.com.br/fsp/1984/08/17/21//42 06488>. Acesso em: 20 mar. 2016.

Candido, Maria R.; Moratelli, Gabriella; Daflon, Verônica T.; Feres Jr, João. 2014. "A cara do cinema nacional: gênero e cor dos atores, diretores e roteiristas dos filmes brasileiros (20022012)". Textos para Discussão GEMAA, Rio de Janeiro, n. 6, p. $1-24$. <http://gemaa.iesp.uerj.br/publicacoes/textos-paradiscussao/tpd6.html>. Acesso em: 5 dez. 2020.

Carneiro, Sueli. 2003. "Mulher em movimento". In: Estudos Avançados. v. 17 n. 49, São Paulo Set./Dez. Disponível em: <http://dx.doi.org/10.1590/S0103-40142003000300008>. Acesso em: 30 nov. 2019.

Carvalho, Noel. 2012. "O produtor e cineasta Zózimo Bulbul - o inventor do cinema negro brasileiro". In: Revista Crioula. n. 12 , nov. Disponível em: 
<http://www.revistas.usp.br/crioula/article/view/57858/60 904>. Acesso em: 3 abr. 2016.

. 2005. "Esboço para uma do negro no cinema brasileiro". In: De, Jeferson; Carvalho, Noel dos Santos. Dogma Feijoada: o cinema negro brasileiro. Col. Aplauso Cinema Brasileiro. São Paulo: Imprensa Oficial.

Ferreira, Ceiça. 2013. Uma representação de si para o mundo: afetos e subjetividades no documentário performático Razón y Palabra, 2013. Disponível em: <http://www.redalyc.org/articulo.oa?id=199525737021>.

Freire, Paulo. 1998. Pedagogia da autonomia. São Paulo: Paz e Terra.

Freitas, Kênia; Almeida, Paulo Ricardo Gonçalves (org.). 2017. Diretoras Negras no Cinema Brasileiro. Brasília/Rio de Janeiro: Caixa Cultural.

Gonçalves, Juliana; Martins, Renata. 2016. "O racismo apaga, a gente reescreve: conheça a cineasta negra que fez história no cinema nacional”. In: Blogueiras Negras. Disponível em: $<$ http://blogueirasnegras.org/2016/03/09/o-racismo-apagaa-gente-reescreve-conheca-a-cineasta-negra-que-fez-historiano-cinema-nacional/.a-nacional/>. Acesso em: 2 abr. 2016.

Lima, Sumaya Machado. 2010. "Lugar de mulher é no cinema... - uma reflexão sobre a "Retomada" no Brasil”. In: Fazendo Gênero 9. Diásporas, Diversidades, Deslocamentos.

Luz, Marco Aurélio. 1992. "Da Porteira para dentro, da porteira para fora”. In: Santos, J. E. (org.). Democracia e diversidade humana: desafio contemporâneo. Salvador: SECNEB, pp. 57-74.

Luz, Narcimária C.P. 2000. Abebe - A criação de novos valores na Educação. Salvador: SECNE.

Scott, Joan Wallach. 1990. "Gênero: uma categoria útil de análise histórica”. In Educação \& Realidade, Porto Alegre, v. 16, n. 2, jul./dez.

Shoat, Ella; Stam, Robert. 2006. Crítica da Imagem Eurocêntrica. São Paulo: Cosac \& Naif.

Silva, Conceição de Maria Ferreira. 2016. Mulheres negras e (in)visibilidade: imaginários sobre a intersecção de raça e gênero no cinema brasileiro (1999-2009). Brasília: Tese (Doutorado em Comunicação), Universidade de Brasília.

Sodré, Muniz. 1988. O terreiro e a cidade. Petrópolis: Vozes. . 2005. A verdade seduzida. Rio de Janeiro: DP\&A.

Souza, Edileuza Penha de. 2013. Cinema na panela de barro: mulheres negras, narrativas de amor, afeto e identidade. Brasília: Tese (Doutorado em Edducação), Universidade de Brasília.

. 2010. "Professoras negras: a escola como tessituras da territorialidade ancestral”. In: Coelho, Wilma de Nazaré Baía; 
Magalhães, Ana Del Tabir. (org.). Educação para diversidade: olhares sobre a educação para as relações étnico-raciais. Belo Horizonte: Mazza.

. 2008. "A ancestralidade africana de Mestre Didi expandindo a intelectualidade negra Brasileira". Texto apresentado no $9^{\circ}$ Congresso Internacional da Associação de Estudos Brasileiros (Brasa). New Orleans: Tulane University. Disponível em: <sitemason.vanderbilt.edu/files/jgM3V6/Souza\%20Edileuza \%20Penha\%20de.pdf>. Acesso em: 12 jan. 2020.

. 2014. Entrevista com a cineasta Adélia Sampaio. Brasília.

. 2014. Entrevista com a atriz Iléa Ferraz. Brasília/Rio de Janeiro.

. 2014. Entrevista com a diretora Luana Paschoa. Brasília/Rio de Janeiro.

Souza, Edileuza Penha de; Silva, Conceição de Maria Ferreira. 2014. Entrevista com cineasta Viviane Ferreira. Brasília.

Stam, Robert. 2008. Multiculturalismo tropical: uma história comparativa da raça na cultura e no cinema brasileiro. São Paulo: Edusp. 